\title{
DROSERA IN THE WESTERN USA — AN UPDATE
}

BARRY A. RICE $\bullet$ Center for Plant Diversity $\bullet$ University of California $\bullet$ One Shields Avenue $\bullet$ Davis • California 95616•USA • bamrice@ucdavis.edu

Keywords: Taxonomy: Drosera, western USA, Drosera anglica, Drosera intermedia, Drosera linearis, Drosera $\times$ obovata, Drosera rotundifolia, Drosera $\times$ woodii.

One of my primary research activities focuses on carnivorous plants in the US states of Montana, Wyoming, Colorado, New Mexico, and westward (but excluding Alaska). Throughout most of this range, the only native species of Drosera are Drosera rotundifolia L., Drosera anglica Huds., and the hybrid Drosera $\times$ obovata Mert. \& Koch. These species are well-known to readers of this journal, and need no further description. In this region, these plants quite often occur in sites that are widely separated, and in some states these taxa are of considerable rarity (for example, in Colorado D. rotundifolia and D. anglica are known at only 4 and 1 sites, respectively; Wolf et al. 2006).

In addition to these species, there have been reports of two additional native Drosera-Drosera intermedia Hayne in northern Idaho (and perhaps adjacent eastern Washington), and Drosera linearis Goldie in Montana.

Drosera intermedia was reported in Boundary County, Idaho by Bursik (1993), as growing with Drosera anglica, but being quite different in form. Additional populations were subsequently found in Custer County, Idaho (L. Kinter, pers. comm. 2017). Of course, the closest other Drosera intermedia plants were on the other side of the continent, so this was considered a find of great interest, and the plants were treated as of special significance.

A few years ago, I decided I needed to visit and assess these plants. Because of my long history of productive engagement with regional staff, I was granted permission to visit the sites, even though the sites were considered potentially quite sensitive. In fact, agency staff even gave me supplemental information on additional Drosera intermedia sites I could visit. There was only one catch - grizzly bear activity had been so high in the area that in some cases I could only go accompanied by experienced staff. Of course, I welcomed this company, as it ensured that I would reach the exact, correct sites.

In late July 2017, I visited the site in Boundary County where the putative Drosera intermedia were first detected. In this case, my wife (Beth Salvia) and I travelled unescorted. The hike was moderately strenuous. This hike (and subsequent plant search) was somewhat stressful because of the grizzly bear issue. We were both armed with cans of bear spray (which is a more effective bear deterrent than firearms), but while we saw plenty of scat, no bears were observed. We did have the good fortune of encountering a mass-flowering of Xerophyllum tenax - ironically called beargrass (Fig. 1).

At the site, the candidate plants were easily detected. They did look strange - they grew in clumped masses

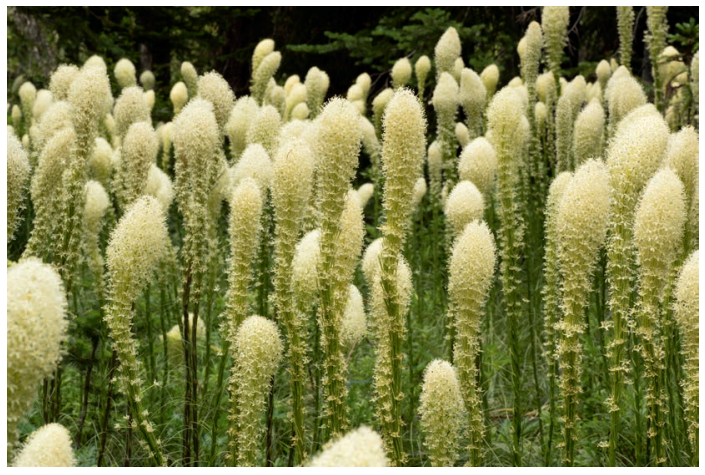

Figure 1: A mass flowering of Xerophyllum tenax in Boundary County, Idaho. 

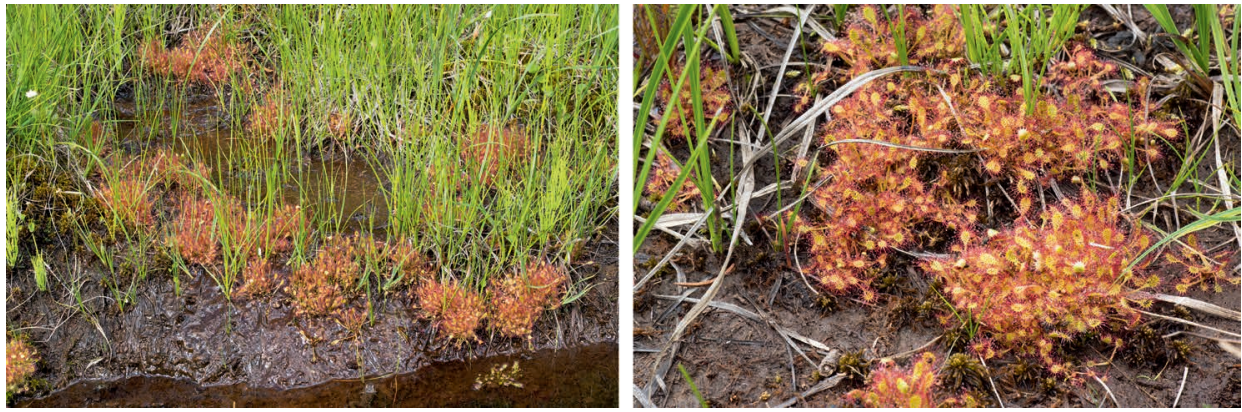

Figure 2: Clumping Drosera anglica at the original "Drosera intermedia" discovery site in Boundary County.

with small leaves (Fig. 2). However, being experienced with the large variation of Drosera anglica as it occurs across the western USA, I quickly realized these were simply Drosera anglica. Viable seed were observed, as was seedling recruitment, so it was clear these plants were not sterile hybrids.

As an aside, I note that there are a number of ways to distinguish Drosera intermedia from Drosera anglica:

1) The leaves of Drosera intermedia are held at a wide of angles around the rosette tip-from nearly vertical to horizontal — while those in Drosera anglica are mostly erect.

2) The inflorescence of Drosera intermedia emerges (often horizontally) from the side of the inflorescence, while the inflorescence of Drosera anglica is more erect.

3) Finally, and most reliably, the seed coats are completely different. The seeds of Drosera intermedia are covered with papillae (bubble-like lumps), while the seeds of Drosera anglica are covered with small, shiny, lens-like surfaces.

The clumpy plants matched Drosera anglica on all counts.

Over the next few days, Beth and I were kindly escorted to a few other sites in Idaho and Washington (Pend Oreille County), where more "Drosera intermedia" plants were reported. In all cases, the plants we found were simply variations of Drosera anglica. Why were these being reported as Drosera intermedia? Because the regional botanists had been told that an uncommon sundew was in the area, and any aberrant Drosera tended to be identified as Drosera intermedia. However, the truth is that they were simply seeing Drosera anglica being strange, as it occasionally is.

Some information for the hungry horticulturists reading this article. I have grown many different Drosera anglica forms - I saw nothing of horticultural significance in these plants. Furthermore, they live at high elevations $(1460 \mathrm{~m})$ in the mountains of Idaho, and probably spend most of the year as hibernacula. These are interesting plants, as are all carnivorous plants, but not of horticultural value.

Incidentally, while we saw black bears on our excursions, we were relieved to not have any encounters with grizzlies.

Several days later, we met with other field workers in Custer County, Idaho, to look for more "Drosera intermedia" populations. Once again, we found Drosera anglica — and at these sites there was really nothing out of the ordinary with these plants. I am guessing that, perhaps some atypically harsh year, someone was surveying these sites and encountered some plants in an abnormal growth state. Whatever the back story might have been, the Custer County plants were mundane Drosera anglica.

If my conclusions about their "rare" Drosera was not what they wanted to hear, my agency hosts didn't show it. In fact, in some ways they were relieved because they could now tell the occasional 

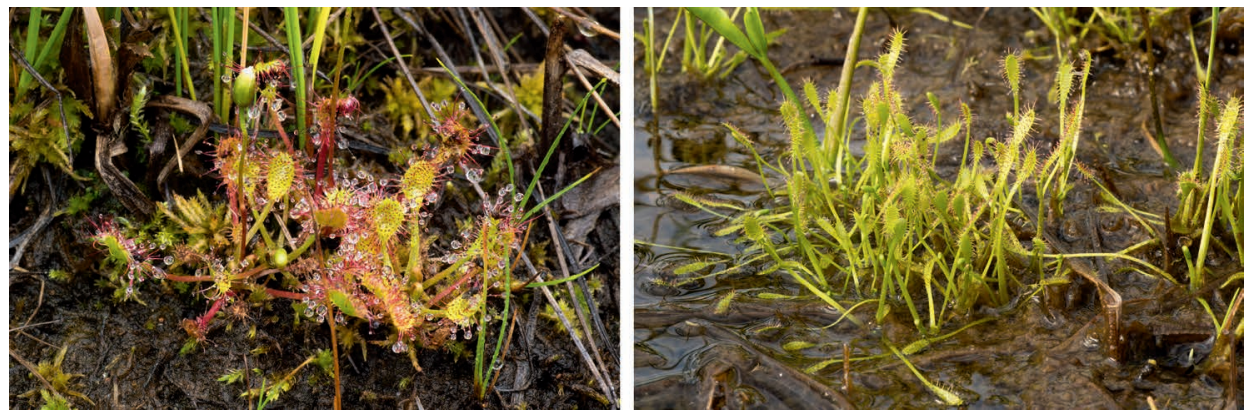

Figure 3: (left): Tiny Drosera anglica in Valley County, Idaho-each plant is only about 2-3 $\mathrm{cm}$ in diameter; (right) nearly anthocyanin-free Drosera anglica in Custer County, Idaho.

carnivorous plant growers that contacted them, that these "rare" plants were really just common after all. (Many carnivorous plant horticulturists had asked them about the plants, to learn if they could collect them.)

Unrelated to these "Drosera intermedia" sites, Beth and I did happen to see some interesting variation in Drosera anglica at other sites in Idaho. At a very remote site in Valley County (that I had visited several years before) we re-observed plants that were only a few $\mathrm{cm}$ across at maturity (Fig. 3 left). Meanwhile, in Custer County, we observed a population which included clumps of extremely lightly pigmented plants - almost completely anthocyanin-free (Fig. 3 right). They were growing in a very wet fen, but within meters of normally pigmented plants that appeared to be growing in identical conditions.

Having put to rest, to my satisfaction, the tale of native Drosera intermedia in the western USA, we travelled eastward to central Montana. The mountains of Montana are fascinating to me for their populations of Drosera linearis. This species is primarily found in the Great Lakes region of the USA and Canada, and sites eastward (Rice et al. 2017). However, there are a few sites in Canada in Alberta (and possibly Manitoba, Saskatchewan, and even British Columbia), extending the range of the plant far to the west (Rice 2019).

Flashback more than a decade

Back around 2005, while conducting background research for my first carnivorous plant book, I encountered references to Drosera linearis in Montana-Montana! I was astonished, but was not able to schedule a trip to see them until 2006. Beth and I had been planning a long vacation in Glacier National Park, so we set aside a few more days for an ancillary expedition to look for these "Drosera linearis."

By that time, I had used research tools at my disposal to determine exactly where these plants occurred. I contacted Montana Natural Heritage Program, and chatted with staff responsible for overseeing the sites. I verified that a visit would not interfere with existing research programs or conservation efforts.

The day of our Drosera linearis trip began poorly. It was late fall, and an early snowstorm had struck the day before. We had to drive several hours to reach the trailhead, and $15-45 \mathrm{~cm}$ of snow covered the ground. During most of the drive, everything was covered by deep snow. But amazingly, when we reached the trailhead, we found that our area had somehow spared the snow, and the ground was clear. 

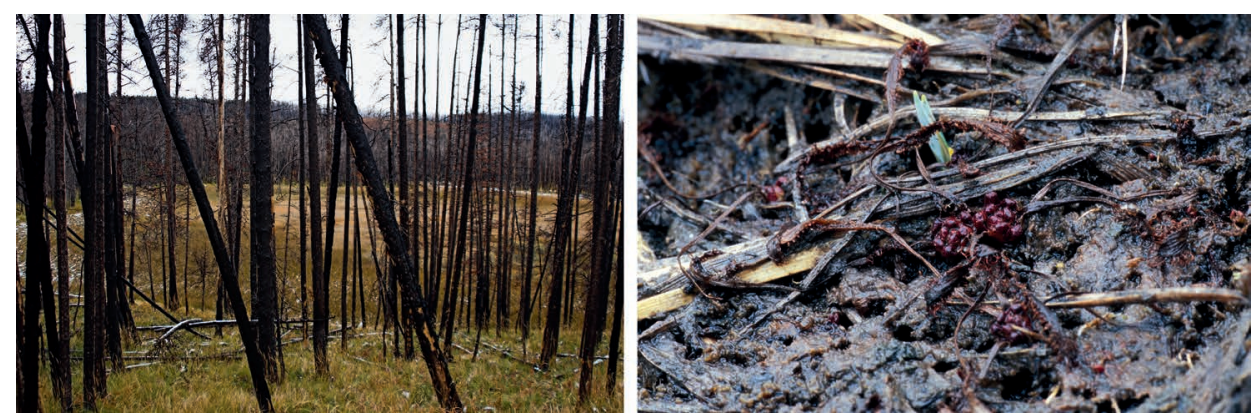

Figure 4: (left): Drosera linearis fen, viewed through a veil of dead, standing trees; (right) Drosera linearis hibernacula in Montana.

This was black bear, grizzly bear, and mountain lion habitat. Topping off our list of hazards, hunters on horseback were common - all day long the mountain silence was punctuated by the crack!-crack!-crack! of long guns being fired. With these dangers present, Beth and I adopted a strategy so we wouldn't be mistaken for animals by predators or overly-weaponized humans. If we ever found something worth hunching over - a plant, insect, fungus - only one of us was allowed to be bent over at a time; the other person had to be standing tall. We did have a close encounter with a few black bears trotting down the trail towards us, but once they saw us, they retreated into the bush at full run.

The hike from trailhead to fen complex was arduous, but we were rewarded with spectacular views of gray owls. All around the trees had been burned by a recent forest fire, which had been so hot that the trees were killed, but not hot enough to burn them to the ground. It was eerie walking among so many dead giants. After a few hours of navigating the network of trails, we reached our site - a compex of clearings in the woods, some of which were fens with open water. Because of our slow progress, we only had time to explore one of the fens. It looked like an open, saturated clearing, but the mucky ground undulated underfoot (Fig. 4 left). It was much like a quaking Sphagnum bog, but the surface consisted of organic muck, apparently bound by the sedges and other emergents. And there - on the delicate floating mucky surface - we saw small, globular Drosera hibernacula with dead, dried leaves (Fig. 4 right). Despite their dried state, we had clearly and unquestionably found Drosera linearis! My first view of the species in the wild! Surely less than optimal, but a spotting nonetheless!

Flashback over... we now return to the current day

During our 2017 trip to Idaho, another journey to see Drosera linearis was essentially compulsory. This time we would be there during the growing season, so I hoped to see more than just hibernacula. We dedicated a few long days for this trip. I hoped to survey all 15 or 20 clearings that I could see on my aerial photos of the region.

When we arrived, I discovered a new hazard - it was an intense fire season and a crown fire in the neighboring mountain peak had a giant smoke plume making it look like an apocalyptic volcano. I chatted with burn crew, and was relieved to learn that access to my desired target sites was not being impacted, at least not yet. However, if the wind changed, we had to be ready to evacuate at a run!

On the first day on the trail, Beth and I headed out early. Our hike was made easier by our prior experience in the region, and there was less uncertainty in our route. We stopped only a few times to 


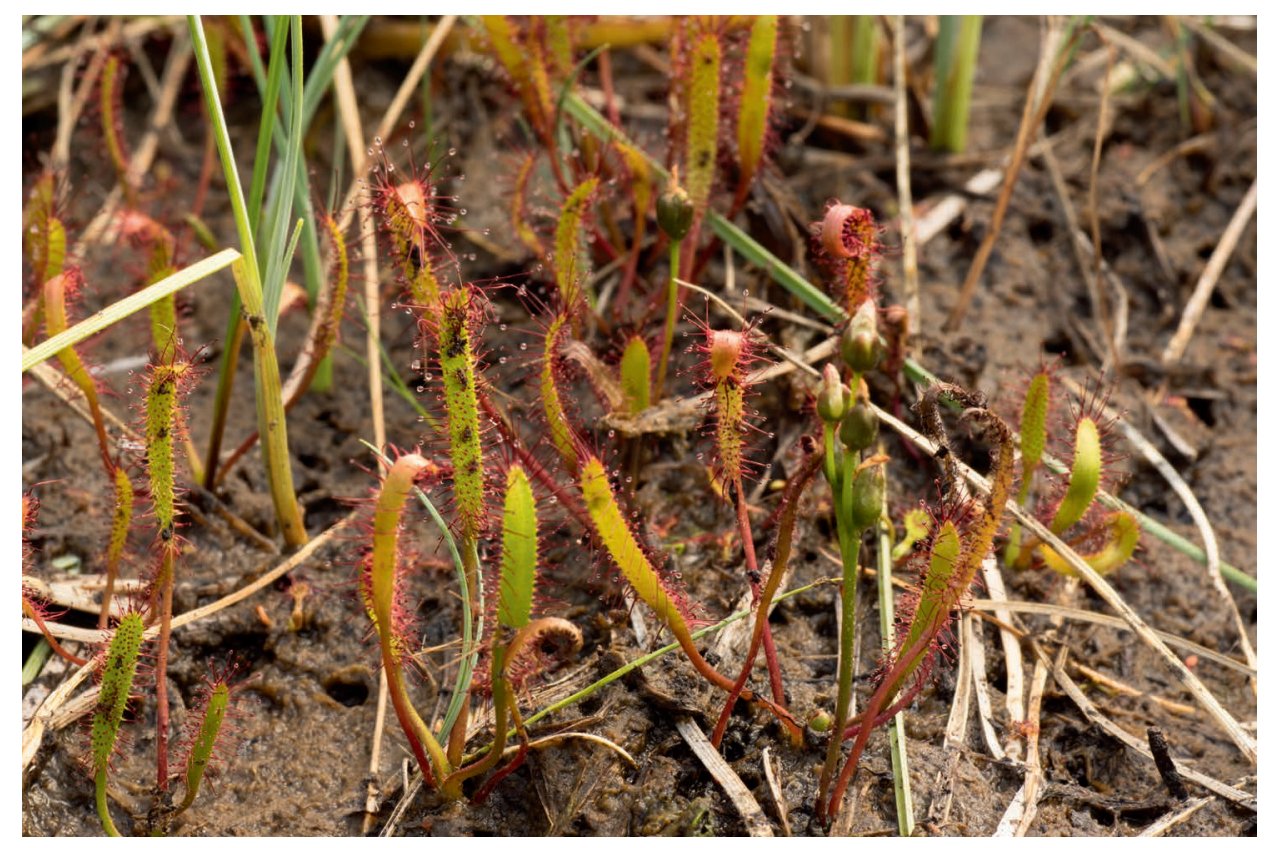

Figure 5: Drosera linearis in Montana.

appreciate the plants and animals along the way, it would have been nice to linger, but I was insufferably anxious to study the Drosera.

As before, we reached a point where our path got as close as it would to our destination fen - at that point we had to bushwhack cross county. The last time (in 2006) this wasn't much of an issue - but now, the travel was considerably different. In 2006, we walked easily in an eerie forest of fire-killed, but standing trees. Now all the trees had fallen over-in random directions - so the ground was piled chest-high with crisscrossed trunks and branches. Our travel slowed to a snail's pace, as there was no simple way to traverse the land. Literally, our progress was reduced to a crawl as we negotiated the sometimes sturdy, sometimes decaying, overlapping fallen trees. Falling off the branches potentially meant falling a meter or more to the ground, and if we fell inelegantly, we might easily snap a leg on the way down. This was not what we expected, but it was what we had to do.

After a tediously long crawl over the landscape-level tree pile, we reached the open fen at last! The Drosera linearis plants were in full growth, mostly past flowering and in fruit (Fig. 5). Interestingly, the plants were spaced apart, unlike other Drosera which can readily be found in clumps or dense patches.

After exploring this site (and finding no other species present), we strategized. We had many other sites in the area we wanted to visit, but progress over the downed trees was glacially slow. Based upon our aerial maps, we found connecting corridors from site to site, which normally I would have avoided because they tend to be choked with vegetation, but in this case, they were our best options.

The rest of the day we investigated clearing after clearing, just to discover that they were all too dry, or were open water sites with no floating muck mat. A great amount of energy was spent to obtain negative results! Ultimately, it was time to leave the fens. The long, laborious crawl over downed trees was unattractive but unavoidable. It took even longer than before because we were 
running out of energy - but in time we finally reached the path and rested and rehydrated before the long hike home.

About only one hour into our return hike, as we passed through a particularly dense stretch of forest, Beth (who was leading) stopped without warning, and I nearly plowed into her. "Bear! Bear!" Yes - there off to the left about 50 meters away, was a huge, shaggy brown beast larger than any bear I had ever before seen. It was busy browsing with its back to us, but as it fed it turned its head enough to one side so I could clearly see the characteristic field marks of a grizzly!

I started talking nonstop babbling sentences - quietly at first, getting progressively louder, to alert the bear as to our presence in as much of a non-alarming way as possible. And indeed - the bear suddenly turned its head in our direction, locked eyes, then exploded away from us in high speed travel over the downed trees. It was both fabulous and appalling to see how effortlessly this massive animal raced, like a giant furry hovercraft, over terrain that was so challenging for us.

The bear gone, and our veins filled with a heady blend of adrenaline, we hiked back to the car at an astonishing pace. I remember very little of that part of the trip.

The next day we again drove to the trailhead. The wind had changed, and parts of our drive were through heavy smoke from the nearby fires. This was not a happy development, as it meant the fires could be moving in our direction.

We hiked back to the complex of fens and clearings. This time, chastened by the discovery of how slow our bushwhack travel was, I set my goals for just one site. (I had spent the evening after our first day looking at the aerial maps, and observed that only one additional site resembled the mucky site where we found Drosera on our first day.) Unfortunately, it involved an even-longer cross-country foray, this time over terrain that also had significant variations in topography. It was also not too far from where we saw the grizzly. Needless to say, it was a challenge to our endurance as well as our nerves, but at last we reached our site - a large grassy lake. Scanning the area with our binoculars, I was able to pick out a large area where the same vegetation grew as at the Drosera site on the previous day. That was our target. We followed the lake edge until I found an approach to the muck mat that didn't require too much wading. We tucked our pants into our socks to block any leeches, and made our way out to the site. The muck mat was very delicate, and Beth and I made sure to keep our distance from each other so at no point did the muck have to support both our weights. Even so, I could see that our presence was causing some damage, which we tried to minimize.

\section{Drosera!}

Yes, we were successful once again. Drosera linearis plants were visible growing on the muck, this time with a significantly higher density than at the first site.

As I examined the plants, I noticed something interesting. There were Drosera anglica plants mixed in with the Drosera linearis! This was exciting to me, as I had seen some references to $D$. anglica in this region. But then, much to my surprise, I observed that the fruit of these plants were sterile - there were no seed being produced. Again and again I examined the plants and found that these Drosera were bearing no seed - they were sterile! Furthermore, there were two morphs of these sterile plants - a long leafed form that looked like typical Drosera anglica (Fig. 6), and a shorter-leafed form that looked more like Drosera rotundifolia (Fig. 7). The inflorescences of both were much taller than the inflorescences of Drosera linearis.

So what were these plants? If I were in California, in areas where both Drosera anglica and Drosera rotundifolia can be found, I would have concluded they were Drosera $\times$ obovata plants. If these were Drosera $\times$ obovata, it would represent a new taxon for the state. Since neither parent was visible at the site, this was a difficult pill to swallow. 


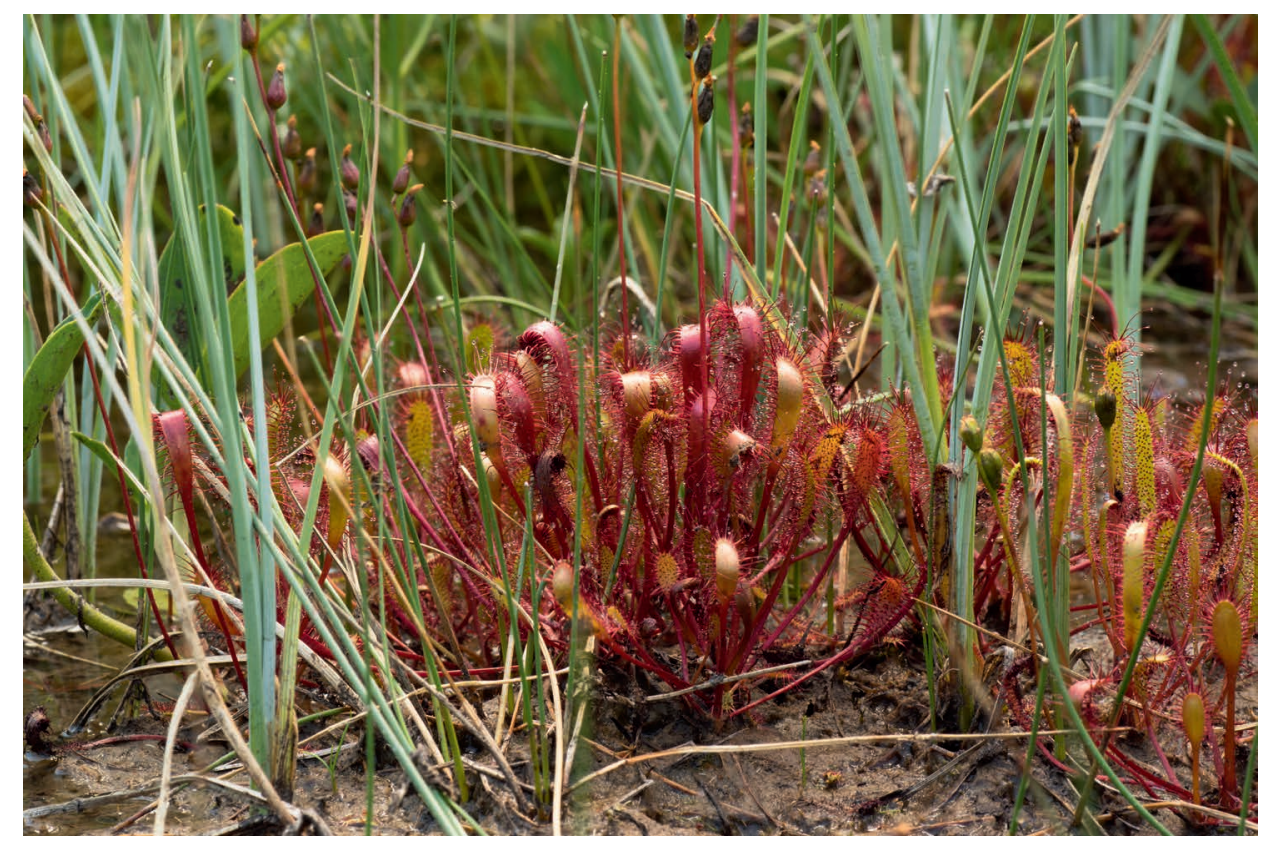

Figure 6: Long-leaved Drosera $\times$ woodii in Montana. Drosera linearis is visible to the right.

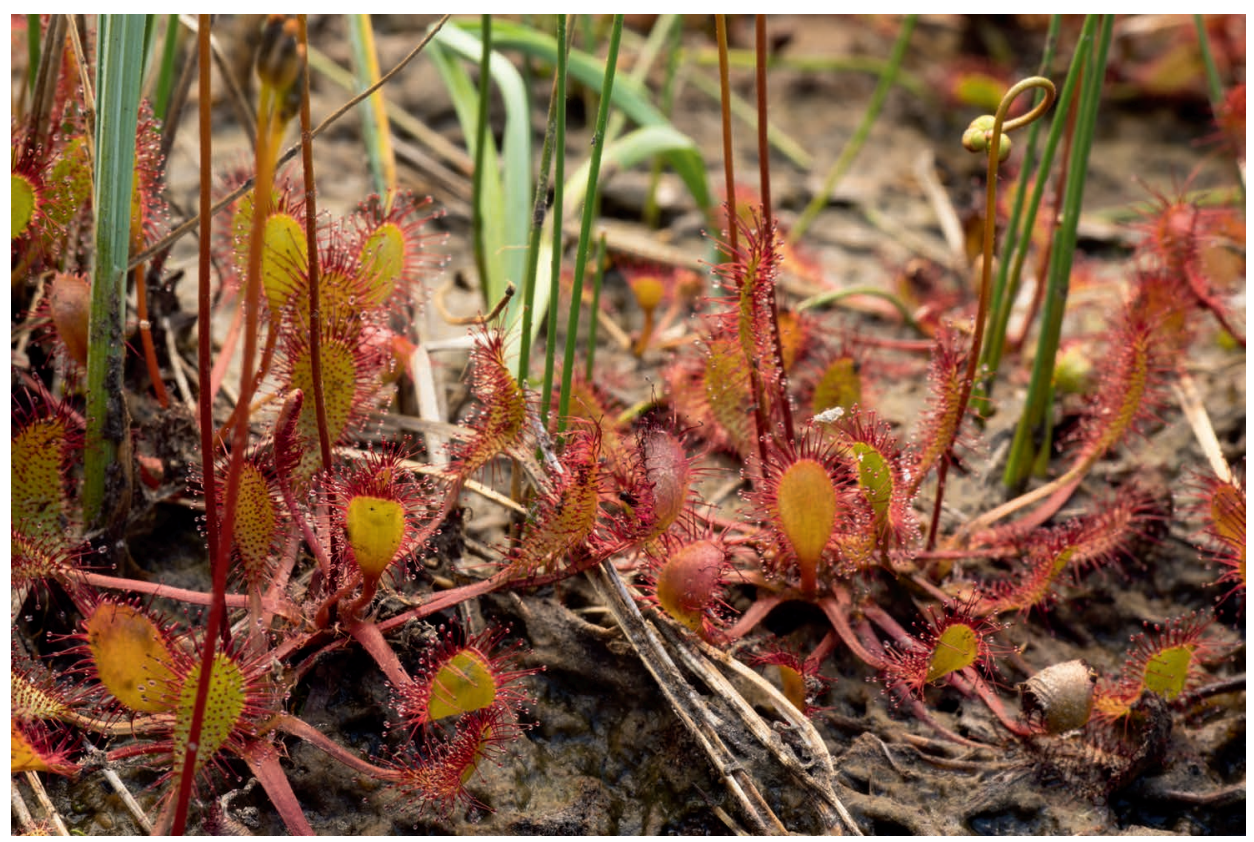

Figure 7: Short-leaved Drosera $\times$ woodii in Montana. 
Another possibility is that these were the hybrid Drosera linearis $\times$ rotundifolia (that is, Drosera $\times$ woodii). This seemed more likely, since it would only require one missing parent - the Drosera rotundifolia. Perhaps a more comprehensive survey of the region would reveal this species. Even if not, it might have occurred at the site in the past, only to perish. I have found places in California where Drosera $\times$ obovata was present, but only one of the parent species occurs. So my current working hypothesis is that the hybrid plants at this site are two strains of Drosera $\times$ woodii. This is extremely exciting, since the only other examples of this hybrid are found far to the east, in the Great Lakes region (Rice et al. 2017).

As much as I wanted to collect herbarium specimens for this new find of scientific interest, I did not have prior permission from the agency overseeing the site, so I documented the plants with photographs and videography only. Upon my return home, I found that these hybrids had been collected from the site, although identified incorrectly as Drosera anglica - so science has been served!

I suspect that some collectors out there would like to grow these plants, but they are not in cultivation. I do not know how they would respond to cultivation-are they as difficult to grow as Drosera linearis? Is there much point, since they look essentially identical to various strains of Drosera anglica or Drosera $\times$ obovata? Is it critical to replicate the chemistry of the muck? Would it be possible to replicate the long months of Montana winter? In any event, visitation to the site is extremely challenging, with many obstacles.

That said, these plants would be wonderful subjects for further study. However, I must note that our short trip resulted in noticeable damage to the muck-mat. I hope that future scientists will do what they can to mitigate damage to this fascinating site.

In closing, I note that I have created a few videos about this site that I have posted on my YouTube channel. Also, Joyce Ferguson has written a wonderfully entertaining poem about this site (crafted when it was thought the sites contained Drosera anglica and Drosera linearis, instead of Drosera $\times$ woodii and Drosera linearis). Enjoy!

Specimens of all the "Drosera intermedia" were herborized for future researchers. Appropriate permissions were obtained prior to making collections.

Acknowledgements: I would like to thank our contacts in Idaho and Montana who either accompanied us on our trips, or provided data support: Braden Burkholder (Montana Natural Heritage Program), Jennifer Costich-Thompson (US Forest Service), Justina Dumont (US Forest Service), Lynn Kinter (Idaho Natural Heritage Program), Andrea Pipp (Montana Natural Heritage Program), Steve Shelly (US Forest Service), Debarah Taylor (US Forest Service).

\section{References:}

Bursik, R.J. 1993. Fen vegetation and rare plant population monitoring in Cow Creek Meadows and Smith Creek Research Natural Area, Selkirk Mountains, Idaho. Idaho Dept. of Fish and Game. https://fishgame.idaho.gov/ifwis/idnhp/cdc_pdf/bursr93a.pdf

Rice, B.A. 1999 The genus Drosera L. (Droseraceae) in the western USA. Phytologia 101(1): 13-25. Rice, B.A., Robinson, A., and Fleischmann, A. 2017. Drosera of North America. In: Drosera of the World, Vol. 2: Oceania, Asia, Europe, North America. Lowrie et al. eds., Redfern Natural History Productions, Poole, Dorset, England.

Wolf, E., Gage, E., and Cooper, D.J. 2006. Drosera rotundifolia L. (roundleaf sundew): a technical conservation assessment. USDA Forest Service, Rocky Mountain Region. https://www.fs.usda. gov/Internet/FSE_DOCUMENTS/stelprdb5250874.pdf 